J. Lake Sci. (湖泊科学), 2012, 24(4):535-540

http: //www.jlakes.org. E-mail : jlakes@niglas.ac.cn

(C) 2012 by Journal of Lake Sciences

\title{
江苏省灌河流域污染特征及污染控制对策”
}

田爱军, 李 冰, 屈 健, 王 水, 高 鸣

(江苏省环境科学研究院,南京 210036)

摘 要: 基于 2008 年江苏省沿海地区灌河流域各城市污染源统计及调查数据,分析灌河流域主要污染物来源构成和污染特 征, 对污染物人河量进行计算及修正. 结果表明: 灌河的 $\mathrm{COD}_{\mathrm{Mn}}$ 人河总量为 $36944.2 \mathrm{t} / \mathrm{a}$, 氨氮人河总量为 $4366.5 \mathrm{t} / \mathrm{a}$, 总氮 和总磷人河总量分别为 $6507.4 \mathrm{t} / \mathrm{a} 、 444.6 \mathrm{t} / \mathrm{a}$, 各污染源均主要来源于农业污染. 同时, 针对灌河流域的污染特征, 明确各 类污染源的治理重点,提出了污染控制对策,为有效保护灌河水环境质量,支撑灌河口和灌河沿线的开发提供依据.

关键词: 污染物来源;污染特征;污染控制对策;灌河;江苏沿海地区

\section{Characteristics of pollutant sources and control measures in Guanhe River Basin, Jiang- su Province}

\author{
TIAN Aijun, LI Bing, QU Jian, WANG Shui \& GAO Ming \\ (Jiangsu Provincial Academy of Environmental Science, Nanjing 210036, P. R. China)
}

\begin{abstract}
Based on municipal pollutant sources data of Jiangsu coastal area in 2008, the main pollutant source composition and pollution characteristics of Guanhe River, the total amount of pollutants into the river was calculated and corrected. Results showed that the total input amount of chemical oxygen demand, ammonia nitrogen, total nitrogen and total phosphorus to Guanhe River was 36944. 2, 4366.5, 6507. 4 and 444.6 t/a, respectively, all of which were mostly originated from agricultural pollution. According to the pollution characteristics of Guanhe River, various pollution sources were clarified. Therefore we put forward countermeasures to control the pollution, which provide a foundation for effectively protecting the Guanhe River water quality and supporting the development of the region.
\end{abstract}

Keywords: Pollutant source; pollution characteristics; pollution control measures; Guanhe River; Jiangsu coastal area

2009 年 6 月 10 日国务院常务会议审议通过了《江苏沿海地区发展规划》, 至此, 江苏沿海地区成为国家 规划发展的战略重点区域,标志着沿海地区发展进人了新阶段 ${ }^{[1-2]}$. 随着经济的快速发展, 区域污染物排放 量逐渐增加, 环境压力日益增大, 2004-2008 年灌河水质污染指数呈逐年升高趋势, 这期间灌河主要污染物 $\mathrm{COD}_{\mathrm{Mn}}$ 、氨氮平均年人海量分别为 $12833.34 、 1242.62 \mathrm{t}^{[3]}$, 陆源污染已导致近岸海域环境及生态损害, 并最 终导致海水富营养化 ${ }^{[4]}$. 灌河口港区是江苏沿海开发的重要节点之一, 灌河岸线开发利用也是区域开发的 重点, 区域内重污染行业突出, 农业面源污染严重, 水环境影响因素复杂, 2007 年仅响水县排人灌河的 $\mathrm{COD}_{\mathrm{Mn}}$ 、氨氮就分别达到 7949、1001 t/a $\mathrm{a}^{[5]}$. 本文通过调查灌河流域污染源, 分析污染源排放量一人河量一人 海断面水质定性关系 ${ }^{[6]}$, 确定影响灌河水质的污染物来源, 制定合理的污染控制措施, 为改善区域水环境质 量,有效削减污染物人海通量,支撑灌河口和灌河沿线的开发提供科学依据.

\section{1 研究区域及研究方法}

\section{1 水文水系特征}

灌河西起灌南县境内与盐河交汇处,向东至燕尾港人海, 是苏北地区最大的人海潮汐河流,也是江苏省沿海

* 江苏省自然科学基金项目(BK2009454)资助. 2011-08-02 收稿;2012-02-07 收修改稿. 田爱军,男,1978 年生, 工程师; E-mail : tianaijun@ hotmail.com. 
地区唯一在干流上没有建闸的天然人海河道, 水利和生态功能独特. 灌河流域面积大, 汇水面积为 $6758 \mathrm{~km}^{2}$, 河道 常年流水充足, 实测最大流速为 $2.34 \mathrm{~m} / \mathrm{s}$, 涨潮平均流量为 $6032 \mathrm{~m}^{3} / \mathrm{s}$, 落潮平均流量为 $4360 \mathrm{~m}^{3} / \mathrm{s}$, 年径流量 为 $40.06 \times 10^{8} \mathrm{~m}^{3}$, 是废黄河以北, 新沂河以南, 淮沭新河以东广大区域的主要人海通道. 灌河干流不同水期 均能达到《地表水环境质量标准》(GB/T 3838-2002) 中 IV 类水质标准, 可满足其功能区划的要求. 通榆河 工程作为苏北地区主要的清水通道, 由南向北穿越灌河, 目前高锰酸盐指数 $\left(\mathrm{COD}_{\mathrm{Mn}}\right)$ 及氨氮无法稳定达到 其水质目标 III类标准. 灌河 7 条主要支流的总氮和总磷亦有不同程度的超标, 其中沂南河受沭阳县境内工 业、生活污水排放的影响, 整体水质处于 $V$ 类水平, 是灌河主要支流中污染最重的河流. 总氮评价标准执行 GB/T 3838-2002 中湖、库标准. 研究区域水系详见图 1 .

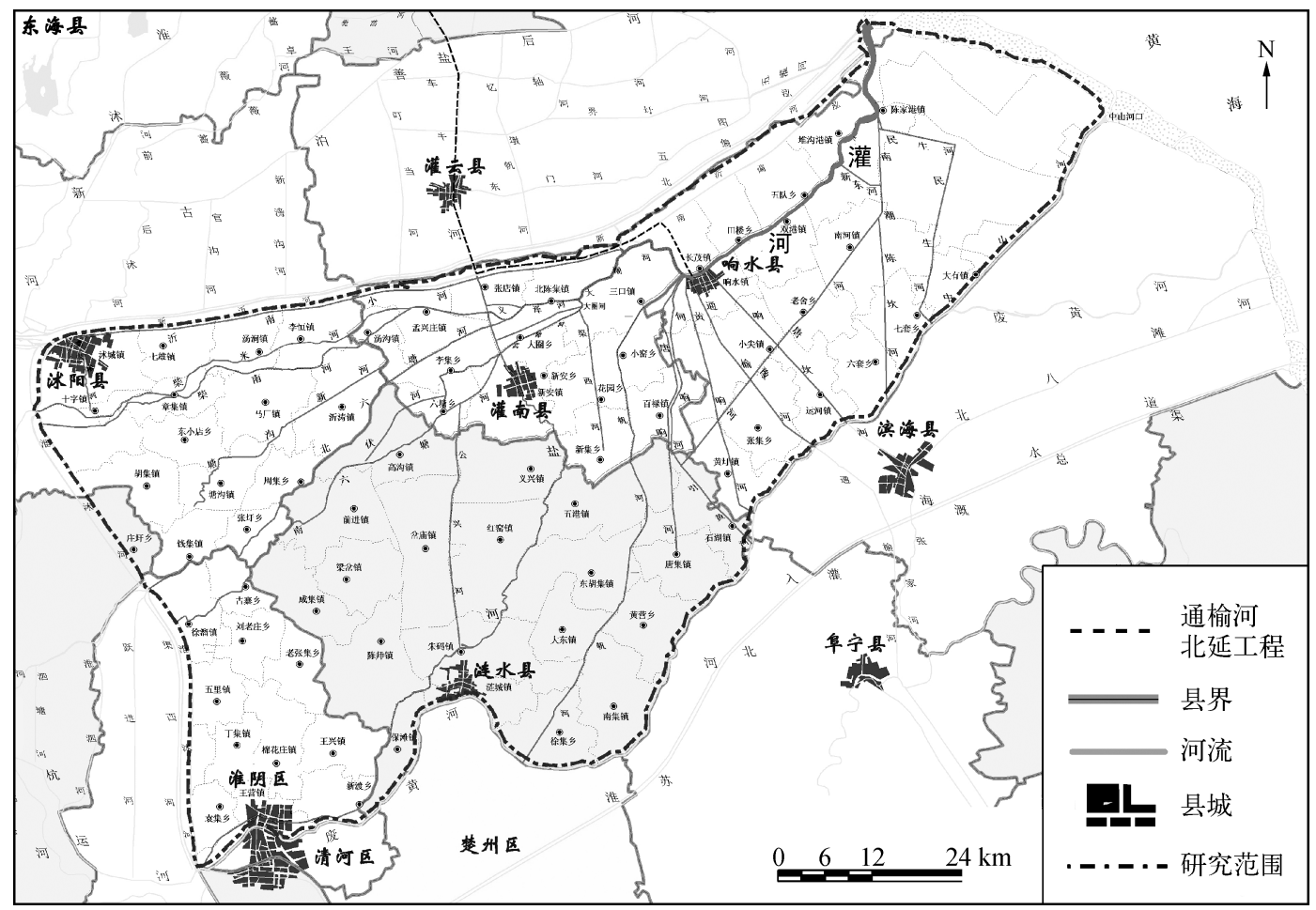

图 1 灌河流域水系

Fig. 1 The water system of Guanhe River Basin

\section{2 研究方法}

1.2. 1 污染源现状调查与核算 根据 2008 年环境统计、企业排污申报和环境保护管理部门重点企业监 管等资料, 利用等标污染负荷排序 ${ }^{[7]}$, 初步确定重点工业污染源名单及其废水和主要污染物排放量. 对不同来源且数据差异较大或缺少主要污染物 $\left(\mathrm{COD}_{\mathrm{Mn}}\right.$ 、氨氮、总氮和总磷) 排放数据的企业进行现场 调查和监测.

根据统计数据 ${ }^{[8-11]}$, 统计并核实调查区域内各乡镇(街道) 的城镇人口、农村人口的数量. 选取有代表性 的镇、村, 抽样调查不同类型居民的生活方式和生活习惯, 确定城镇和农村人均综合用水量、人均综合排水 量、生活污水中污染物平均质量浓度等参数. 参照《全国水环境容量核定技术指南》中确定的华东地区人均 污染物排放当量对生活污染的统计结果进行校核.

农业面源污染主要包括种植业、畜禽养殖业和水产养殖业污染, 种植业污染物排放量计算公式为:

$$
W_{\text {种植 }}=M \cdot \alpha_{1}
$$

式中, $W_{\text {种植 }}$ 为种植业污染物排放量 $(\mathrm{t} / \mathrm{a}) ; M$ 为耕地面积 $\left(\mathrm{hm}^{2}\right) ; \alpha_{1}$ 为种植业排污系数 $\left(\mathrm{t} /\left(\mathrm{hm}^{2} \cdot \mathrm{a}\right)\right)$. 
畜禽养殖业污染物排放量计算公式为:

$$
W_{\text {育离 }}=\delta_{1} \cdot t \cdot N_{\text {畜离 }} \cdot \alpha_{2}+\delta_{2} \cdot t \cdot N_{\text {育离 }} \cdot \alpha_{3}
$$

式中, $W_{\text {畜离 }}$ 为畜禽养殖业污染物排放量 $(\mathrm{t} / \mathrm{a}) ; \delta_{1}$ 为畜禽个体日产粪量 $(\mathrm{kg} /($ 头 $\cdot \mathrm{a})) ; t$ 为饲养期 $(\mathrm{a}) ; N_{\text {畜离 }}$ 为饲养数; $\alpha_{2}$ 为畜禽粪中污染物平均含量 $(\mathrm{t} / \mathrm{kg}) ; \delta_{2}$ 为畜禽个体日产尿量 $(\mathrm{kg} /($ 头 $\cdot \mathrm{a})) ; \alpha_{3}$ 为畜禽尿中污 染物平均含量 $(\mathrm{t} / \mathrm{kg})$.

水产养殖业污染物排放量计算公式为:

$$
W_{\text {水产 } \mathrm{p}}=M_{\text {水产 }} \cdot \alpha_{4}
$$

式中, $W_{\text {水产 }}$ 为水产养殖业污染物排放量 $(\mathrm{t} / \mathrm{a}) ; M_{\text {水产 }}$ 为水产养殖业面积 $\left(\mathrm{hm}^{2}\right) ; \alpha_{4}$ 为水产养殖业排污系数 $\left(\mathrm{kg} /\left(\mathrm{hm}^{2} \cdot \mathrm{a}\right)\right)$.

1.2 .2 污染物入河量计算 工业污染物人河量计算公式为:

$$
W_{\text {工 }}=\left(M_{\text {工 }}-\theta_{1}\right) \exp \left(\frac{-k x}{u}\right)
$$

式中, $W_{\text {工 }}$ 为工业污染物人河量 $(\mathrm{t} / \mathrm{a}) ; M_{\text {工 }}$ 为工业污染物排放量 $(\mathrm{t} / \mathrm{a}) ; \theta_{1}$ 为污水处理后污染物削减量 $(\mathrm{t} / \mathrm{a}) ; k$ 为水质降解系数 $\left(\mathrm{s}^{-1}\right) ; x$ 为点源距离人河排污口的距离 $(\mathrm{m}) ; u$ 为平均流速 $(\mathrm{m} / \mathrm{s})$.

农村生活污染物人河量计算公式为:

$$
W_{\text {生 } 1}=N_{\text {农 }} \cdot \delta_{3} \cdot \beta_{1}
$$

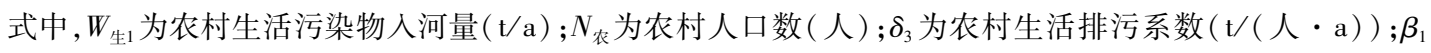
为农村生活污染物人河系数.

城镇生活污染物人河量计算公式为:

$$
W_{\text {生 } 2}=\left(N_{\text {城 }} \cdot \delta_{4}-\theta_{2}\right) \beta_{2}
$$

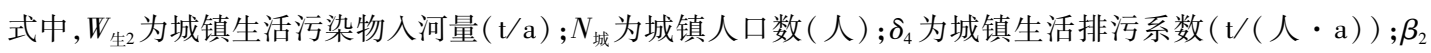
为城镇生活污染物人河系数; $\theta_{2}$ 为污水处理后污染物削减量 $(\mathrm{t} / \mathrm{a})$.

种植业污染物人河量计算公式为:

$$
W_{\text {种植 }}=W_{\text {种植 }} \cdot \beta_{3} \cdot \gamma_{1}
$$

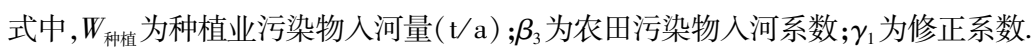

养殖业污染物人河量分为畜禽养殖和水产养殖两部分, 计算公式为:

$$
W_{\text {养殖 }}=W_{\text {育离 } \mathrm{p}} \cdot \beta_{4}+W_{\text {水产 } \mathrm{p}} \cdot \beta_{5}
$$

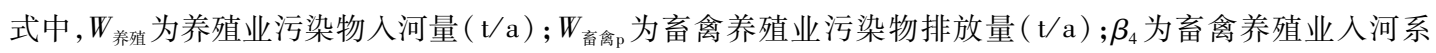
数; $W_{\text {水产 }}$ 为水产养殖业污染物排放量 $(\mathrm{t} / \mathrm{a}) ; \beta_{5}$ 为水产养殖业入河系数.

污染源人河系数的确定: 人河系数根据研究区和污染源类型而定, 主要有收集现有成果确定 ${ }^{[12]}$ 和开展 小区试验确定两种获取方式, 根据对现有资料 ${ }^{[13]}$ 汇总, 初步确定工业、城镇生活、农村生活污染源人河系数 分别为 $0.9 \sim 1.0 、 0.7 \sim 0.9 、 0.2 \sim 0.4$; 农业面源包括种植业、畜禽养殖、水产养殖污染源, 其人河系数分别 为 $0.1 \sim 0.3 、 0.1 \sim 0.5 、 0.1 \sim 0.5$.

\section{2 结果与分析}

\section{1 区域污染构成}

灌河流域内污染物排放量大, 主要来源于农业污染, $\mathrm{COD}_{\mathrm{Mn}}$ 占总量的 $46.6 \%$, 氨氮占 $50.0 \%, \mathrm{TN}$ 占 $50.7 \%, \mathrm{TP}$ 约占 $48.3 \%$; 其次是生活污染, $\mathrm{COD}_{\mathrm{Mn}}$ 占总量的 $39.4 \%$; 工业污染所占份额较小, $\mathrm{COD}_{\mathrm{Mn}}$ 占总量 的 $14.0 \%$ (表 1 ). 
表 1 灌河流域不同污染源污染物人河量

Tab. 1 The pollutants of different sources into the Guanhe River Basin

\begin{tabular}{|c|c|c|c|c|c|c|c|c|}
\hline \multirow{2}{*}{ 污染源 } & \multicolumn{2}{|c|}{$\mathrm{COD}_{\mathrm{Mn}}$} & \multicolumn{2}{|c|}{$\mathrm{NH}_{3}-\mathrm{N}$} & \multicolumn{2}{|c|}{$\mathrm{TN}$} & \multicolumn{2}{|c|}{ TP } \\
\hline & 排放量/(t/a) & 比例 $/ \%$ & 排放量/(t/a) & 比例 $/ \%$ & 排放量/ $(\mathrm{t} / \mathrm{a})$ & 比例 $/ \%$ & 排放量/ ( $\mathrm{t} / \mathrm{a})$ & 比例 $/ \%$ \\
\hline 生活污染源 & 14548.6 & 39.4 & 1733.5 & 39.7 & 2531.6 & 38.9 & 195.0 & 43.9 \\
\hline 工业污染源 & 5190.1 & 14.0 & 450.1 & 10.3 & 675.1 & 10.4 & 34.7 & 7.8 \\
\hline 农业污染源 & 17205.5 & 46.6 & 2182.9 & 50.0 & 3300.7 & 50.7 & 214.9 & 48.3 \\
\hline 合计 & 36944.2 & 100.0 & 4366.5 & 100.0 & 6507.4 & 100.0 & 444.6 & 100.0 \\
\hline
\end{tabular}

\section{2 区域污染特征}

2.2.1 工业污染特征 (1) 结构性污染突出. 研究区工业污染源行业分布较广泛, 但化工行业、食品制造业、 纺织印染行业、造纸行业等重污染企业在区域工业经济中占有主导地位, 各项排污指标均占区域工业排污 总量的 $80 \%$ 以上. 其中食品制造业是废水排放量和 $\mathrm{COD}_{\mathrm{Mn}}$ 排放量最大的行业, 废水排放量占总量的 $28.4 \%$, $\mathrm{COD}_{\mathrm{Mn}}$ 排放量占总量的 $55.0 \%$ （图 2). (2) 落后产能比重大、污染治理难度高. 化工行业和食品制造业是研 究区污染贡献率最高的两类行业, 其中化工企业主要分布在化工园区, 但园区数量偏多, 规模整体偏小, 人 区项目主要是从苏南及周边省份转移来的三类中间体项目,产业雷同, 且档次低、规模小、污染重、治理难; 食品制造业分布较分散, 在响水县、灌南县、涟水县、沭阳县和淮阴区的多个乡镇均有分布, 因此逐步淘汰落 后产能,加强污染源监管是研究区污染治理的首要任务.
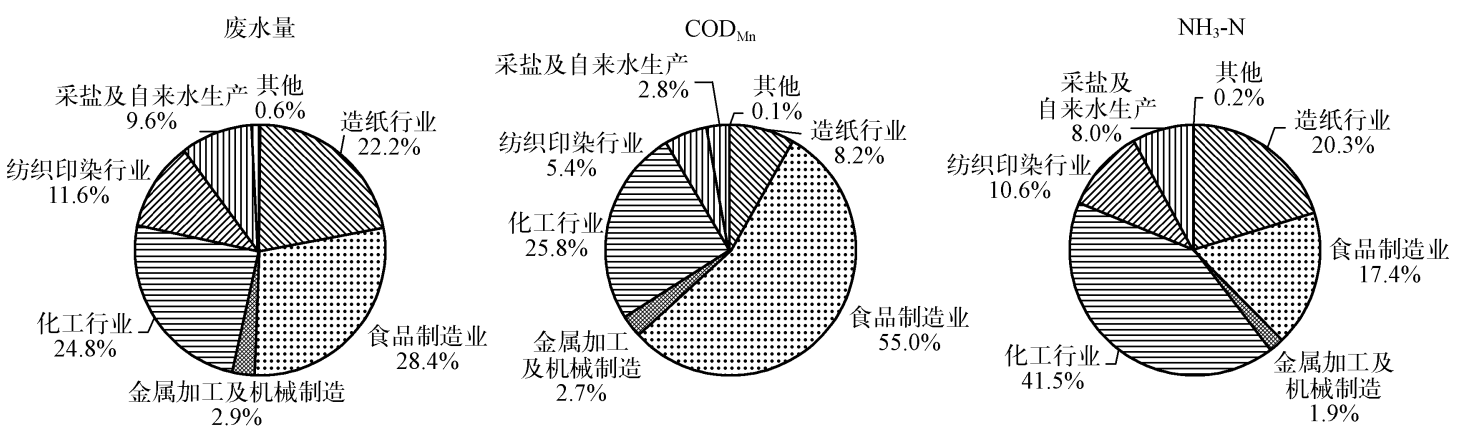

TP

TN
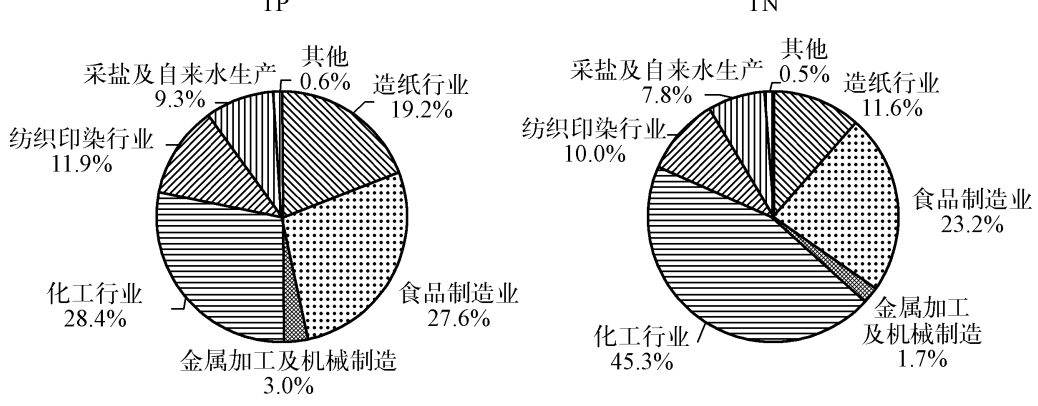

图 2 重点工业行业污染排放分布

Fig. 2 The composition of pollution discharge amount of key industries

2.2 .2 生活污染特征 研究区生活污染物排放量占区域排污总量的 39.0\%. 区内 2008 年已建成的城镇污水 处理厂的处理能力为 $9.0 \times 10^{4} \mathrm{t} / \mathrm{d}$, 但配套管网建设不足, 实际处理量仅有 $3.3 \times 10^{4} \mathrm{t} / \mathrm{d}$, 其中生活污水处理 量为 $2.4 \times 10^{4} \mathrm{t} / \mathrm{d}$, 从而导致研究区生活污水集中处理率较低, 仅为 $13.4 \%$. 其中灌南县城目前尚无运行的 城镇污水处理厂.

2.2 .3 农业污染特征 研究区农业面源污染尚未得到有效控制. 区域内化肥施用强度大, 平均化肥施用量约 
为 $525.00 \mathrm{~kg} / \mathrm{hm}^{2}$, 高于全国平均水平 $\left(306.45 \mathrm{~kg} / \mathrm{hm}^{2}\right)$. 种植业排放的 $\mathrm{COD}_{\mathrm{Mn}} 、 \mathrm{NH}_{3}-\mathrm{N} 、 \mathrm{TP}$ 分别达农业面源 污染总量的 $26.9 \% 、 42.5 \%$ 和 $43.1 \%$.

\section{3 污染治理措施}

2.3.1 优化产业结构和布局 对研究区内所有工业企业, 特别是未人园的企业进行分类清理整顿. 逐步淘汰 落后生产能力, 保留的企业逐步搬迁进人工业园区或工业集中区. 重点企业必须推行全过程清洁生产, 中水 回用, 发展循环经济. 加快现有工业园区的环境基础设施建设, 推进循环经济和生态工业园的创建. 新建项 目必须符合《关于明确苏北地区建设项目环境准人条件的通知》(苏环管 [2005]262 号) 中的相关要求, 并全 部进人基础设施完善的工业园区,实现集约化发展.

2.3 .2 加强生活污水处理能力建设 加快城镇污水处理厂建设, 进一步扩大城镇生活污水处理厂规模. 研究 区内灌南、沭阳、涟水、淮阴区、涟水、泗阳城镇污水集中处理率 2012 年达到 40\% 以上,2015 年达 75\% . 同时 加快配套截污管网建设, 提高污水管网覆盖率, 切实提高截污能力. 2012 年规划区范围内各城镇管网覆盖率 达到 40\% 以上,2015 年达到 75\%。

因地制宜, 在实施农村改则的基础上, 建设农村分散式小型生活污水处理设施, 或者利用村庄或住户周 围自然环境建设生态组合处理工程, 削减氮磷污染. 积极开展农村生活污水资源化技术试点工作. 重点建设 涟水等地的农村小型生活污水处理设施.

2.3 .3 加快实施绿色农业工程 实施生态农业工程, 积极鼓励、引导区域内沿河农户大力发展生态农业、有 机农业和节水农业, 全面推广测土配方施肥和农药减量增效控污等先进适用技术. 利用不同植被对土壤养 分吸收能力的互补性和对农业非点源污染的截留、过滤能力, 在农田与水体之间建立合理的植被过滤带, 减 少地表径流.

取缔“禁止排放区”内的畜禽养殖, 严格禁止在通榆河一级保护区内新建畜禽养殖场. 排放区外的畜禽 养殖场必须做到粪便资源化利用, 建设污水收集和处理设施, 实现废水达标排放. 推广发酵床生态养殖技 术; 推行干清粪作业, 减少污水和粪便流失; 修建秸秆、粪便、生活垃圾等固体废弃物发酵池, 处理有机垃圾 等废弃物,生产沼气和有机肥, 实现资源循环利用.

2.3 .4 加强环境监控预警能力 加大对排污单位的监管力度. 各排污口安装自动监控装置, 与各地的污染源 监控中心联网, 实行实时监控、动态管理, 监控指标包括废水流量、 $\mathrm{COD}_{\mathrm{Mn}} 、 \mathrm{NH}_{3}-\mathrm{N} 、 \mathrm{TP}$ 等. 加强现场监督检查, 对偷排、超标排放等违法排污企业按高限予以处罚, 直至关停. 结合流域、区域污染容量管理要求, 健全完善 企业排污总量控制和排污许可证制度, 做到持证排放、按量排污, 把各项减排措施落实到每一个工业点源. 在加大监控的深度和广度的同时, 建立一套联动的环境预警和应急响应预案, 提高环境预警能力, 以预防突 发环境事故,及时采取有效的应对措施.

\section{3 结论}

1) 灌河流域 $\mathrm{COD}_{\mathrm{Mn}} 、 \mathrm{NH}_{3}-\mathrm{N} 、 \mathrm{TP} 、 \mathrm{TN}$ 均主要来源于农业污染源, 四项指标分别占区域排污总量的 $46.6 \% 、 50.0 \% 、 48.3 \%$ 和 $50.7 \%$; 三类污染源排污量大小为农业面源 > 生活污染源 >工业污染源.

2) 种植业是农业面源的主要污染来源. 实施生态农业工程, 积极调整农业结构. 大力发展生态农业、有 机农业和节水农业, 全面推广测土配方施肥和农药减量增效控污等先进适用技术, 将有效削减农业污染排 放量.

3) 化工行业、食品制造业、纺织印染行业、造纸行业等重污染企业为区域工业经济主导产业,各项排污 指标均占区域工业排污总量的 $80 \%$ 以上. 其中食品制造业和化学工业是区域污染贡献率最高的两个行业, 必须通过优化产业结构和布局, 以有效控制工业污染排放.

4) 生活污水集中处理率过低, 区内 2008 年已建成的城镇污水处理厂的处理能力为 $9.0 \times 10^{4} \mathrm{t} / \mathrm{d}$, 实际 生活污水处理量为 $2.4 \times 10^{4} \mathrm{t} / \mathrm{d}$. 生活污水集中处理率仅为 $13.4 \%$, 且灌南县城尚无运行的城镇污水处理 厂. 加快区域污水处理设施建设已迫在眉睫.

\section{4 参考文献}

[1] 李 冰, 吴海锁. 从决策源头保护生态敏感区一一江苏沿海地区发展规划环评经验. 环境保护, 2009,21 :46-48. 
［2］刘振亚. 基于江苏沿海开发生态实现的生态伦理原则研究.生态经济,2010,(3):162-165.

[3] 马洪瑞,陈聚法,崔 毅等. 灌河和射阳河水质状况分析及主要污染物人海量估算. 渔业科学进展, 2010,31 (3): 92-99.

［4］金浩波,黄 卫. 江苏沿海地区水污染现状及防治对策. 环境导报,2001,(1):42-44.

[5] 陈小丽.灌河响水段纳污能力及污染总量控制分析.科协论坛,2009,3:118.

[6] 张利民, 刘伟京, 尤本胜等. 太湖流域漕桥河污染物来源特征. 湖泊科学, 2009,22(10): 1150-1155.

[ 7 ] 钟定胜,张宏伟. 等标污染负荷法评价污染源对水环境的影响. 中国给水排水,2005,(5):106-108.

[ 8 ] 连云港市统计局. 2009 连云港统计年鉴. 北京:中国统计出版社,2009:54-60.

[ 9 ] 盐城市统计局. 2009 盐城统计年鉴. 北京:中国统计出版社,2009:86-91.

[10］宿迁市统计局. 2009 宿迁统计年鉴. 北京:中国统计出版社,2009:39-44.

[11] 淮安市统计局. 2009 淮安统计年鉴. 北京:中国统计出版社,2009:76-81.

[12] 河海大学. 江苏省主要水域纳污能力核定和限制排污总量研究. 南京: 河海大学出版社, 2007:147-186.

[13] 孟 伟. 流域水污染物总量控制技术与示范. 北京: 中国环境科学出版社, 2008:50-56. 